\title{
ERRATA TO "TABLE OF THE ZEROS OF THE LEGENDRE POLYNOMIALS OF ORDER 1-16 AND THE WEIGHT COEFFICIENTS FOR GAUSS' MECHANICAL QUADRATURE FORMULA"1
}

\author{
ARNOLD N. LOWAN, NORMAN DAVIDS, AND ARTHUR LEVENSON
}

The following errors should be noted.

Page 740. The statement "where $\xi$ is a point in the interval $(p, q)$ and $k_{n}$ is the normalizing factor for $P_{n}(x)$, which is equal to

$$
\left(\frac{2 n+1}{q-p}\right)^{1 / 2} . "
$$

should be replaced by "where $\xi$ is a point in the interval $(p, q)$ and $k_{n}$ is

$$
\left({ }_{2 n} C_{n}\right)(2 n+1)^{1 / 2} /(q-p)^{n+1 / 2} . "
$$

The bottom of the same page should contain the following:

"Note. On this and the previous page, the subscripts of $x_{n}$ and $a_{n}$ are allowed to range from 1 to $n$. In the table, however, it seemed more convenient to change the notation slightly, and permit both positive and negative subscripts. Thus for $n=3$, the roots are $x_{-1}$, $x_{0}, x_{1}$. Roots with negative subscripts can be obtained by symmetry from those tabulated. Similarly for the entries $a_{n}$."

Page 741. The value of $x_{2}$ should read 0.519096129206812 .

Page 742. The value of $x_{1}$ should read $x_{1}=0.125233408511469$.

The value of $x_{2}$ should read $x_{2}=0.367831498998180$.

New York City

Received by the editors March 18, 1943.

1 Bull. Amer. Math. Soc. vol. 48 (1942) pp. 739-743.

\section{ERRATA, VOLUME 49}

E. J. Gumbel, On the plotting of statistical observations, abstract 49-9-238.

p. 698 , line 5 of the abstract. Instead of "The correction $\Delta$ for the rank is unlimited and possesses a mode, $\Delta$ increases" read "If the variate is unlimited and possesses a single mode the correction $\Delta$ for the rank increases." 
